\title{
Book Review: The Rise of the Network Society - The Information Age: Economy, Society, and Culture
}

\author{
Taner Kizilhan \\ Anadolu University, Turkey \\ Sevil Bal Kizilhan \\ Baskent University, Turkey
}

There are many studies which examine the relationship of technology with economy, society, and culture. Manuel Castells is one of the researchers who have worked on this subject. He enhanced the discussions with sociological evaluations based on field research; he has done this within the concept of the "Network Society." Castells is a Professor Emeritus of Sociology and Planning at the University of California, Berkeley. He is also the Wallis Annenberg in Communication Technology and Society at the University of Southern California, Los Angeles, as well as being a Research Professor at the Open University at Catalonia in Barcelona, Spain. He is a Distinguished Visiting Professor of Technology and Society at Massachusetts Institute of Technology (MIT) and a Distinguished Visiting Professor of Internet Studies at Oxford University in United Kingdom. He is a recipient of numerous academic awards. He is a fellow of the European Academy, a fellow of the Spanish Royal Academy of Economics, and a Corresponding Fellow of the British Academy. He has received 14 honorary doctorates from the universities around the world. He has authored 22 books, among which is the trilogy "The Information Age: Economy Society, and Culture" first published by Blackwell in 1996-8, and translated into 20 different languages.

Castell's book, which was reviewed in this article, is the first part of his "The Information Age: Economy Society, and Culture" study. The author states that, this trilogy was prepared to be a single work, but then with the contributions of the editor, it was divided into three books by making each part of the study a separate book. In this article, only the trilogy's first book "The Rise of the Network Society: The Information Age: Economy, Society, and Culture - Volume 1" was reviewed. The reviewed version is the second edition of the book (597 pages), which was published by Wiley-Blackwell in Oxford-UK in 2010.

The assumption that the information technologies' brought a new form of social organization, which was conceptualized as the "Network Society", is the starting point in the "Rise of the Network Society" book. In the Network Society social, economic, political, cultural, and technological transformations are produced and reproduced through individuals' digital interactions.

In the prologue of the book, under the "Net and Self" title, historical transformations of relationship between technology and society in different counties were given. Also, a discussion about societies' modes of development and modes of production were presented within the framework of Informationalism, Industrialism, Capitalism, and Statism notions. In this discussion, Castells mentions about Information Technology Revolution's effects on globalization, as a form of reorganization of the capitalist system within the framework of production, experience and power relations. He conceptualizes this new economic system as "Informational Capitalism". Then, he emphasizes new information technologies' constructive character on identity. At the end of this chapter, the author gives information about the methodological background of the study. 
In the first chapter of the book "Information Technology Revolution", was evaluated as a historical momentum that was as effective as the Industrial Revolution of the $18^{\text {th }}$ century. After this revolution, for the first time in history, humankind became the manufacturing power itself rather than being the decision-maker subject of the production processes. This is the result of the increasing cohesion between mind and machines. The enabling conditions of this revolution were discussed over subheadings like electronics and information, the creation of the Internet and its process of expansion with network technologies, technological divide and transformation's social context. Then, an "Information Technology Paradigm" was set forth by considering actors, sites and models of the Information Technology Revolution. Because, according to Castells, the core of the transformation of this revolution is the information and communication technologies; and new information technologies aren't just application tools but at the same time they are processes to be developed.

In the second chapter of the book, the character and components of the "Informational Economy", which are expressed as a new economic order on the basis of information, were mentioned. The reason why economy is defined as "Informational" rather than just being based on information is because it requires a new social organization and brings this social organization together with itself. In this context, Castells examines globalization and networks as components of the economy. Another discussion in this chapter is about what kind of systematical basis efficiency, competitiveness and profitability has in the Informational Economy. In the 20th century the new information technologies became the basic mechanism in all of the strategies which are used for profit maximization. Competition is insisting on new rules and technologies, both in local and global levels, and the ones, who cannot adapt these, are getting excluded from the economic system. Also, in this chapter, historical specificity of the informational economy and in which contexts it intersects with capitalist system were discussed. After an evaluation on the rise of global economy, it's relationship with regionalization, political economy of globalization, networks, information technology, and new economy were examined.

In the third chapter, it is addressed that the information economy's defining character is the development of a new organizational logic, which is related with technological transformation process, but not directly dependent on this process. In this context, a network schematic, which involves informational economy's culture, institutions and organizational practices, was included to study. At this point, the transformation of the organization in the transition capitalism through informationalism is considered. In this regard, a historical flow, which contains transition from mass production to flexible production, the crisis of the large corporations, emergence of management -worker cooperation, total quality control, corporates' strategic alliances, the establishment of a global network, was followed. Castells explains the establishment of the "network institution" through this process too. He emphasizes that computer networks are the sine qua non of companies' establishing strategic alliances, execution of the contract jobs and execution of the complex network of small units' independent decision-making process. Whereas creating networks not just allows the one to keep up with constantly updated information, but also it makes it possible to share the costs and risks, and it is quite difficult to stay out of such networks. Castells supports this theoretical framework by creating a typology of business networks in East Asia, and then moving from this typology he evaluates the relationship between global companies, information technology and network institution. At the end of the chapter Castells mentions "The Spirit of Informationalism" by referring Weber's "The Protestant Ethic and the Spirit of Capitalism" work. At this point, he expresses that for the first time in the whole history the basic unit of organization is not the subject but the "network". Also, he says that the culture of the informational economy is a multi-faceted virtual culture and the spirit of the informational economy is a creative destruction culture.

The fourth chapter of the book considers the transformation of work practices and forms of employment. In this context, subtitles like flexible working, the economy shaped by service sector, new occupational structure were evaluated. After these evaluations, Castells discusses what the new 
employment structure means for the information society and what the role of the new information technologies is in these transformations. According to Castells, information technologies and restructuring of labor-capital relations via these technologies should be considered with the notions of "Social Dualism" and "Fragmented Societies". After preparing these discussion grounds, Castells, statistically analyzes the professional structures and the employment structure in the G-7 Countries. After these discussions and analyses, he asks the question of if there is a global labor force, and he says there isn't a global labor force, but the labor force is becoming more dependent on each other globally, as the answer of this question.

From the fifth chapter of the book, the evaluations focused on the economy, which were highly contemplated until the fourth chapter, leave their place to emphasis on culture and society. In this chapter, Castells speaks of an electronic communications integration which was intertwined with in computer communications, new media and social networks, and he defines this integration as "The Culture of Real Virtuality". Internet is the universal, interactive, computerized communication tool of information age, and computer-mediated communication is based on "interaction" unlike McLuhan Galaxy. The Culture of Real Virtuality is the result of the strong impact of the new communication system, which is determined by social interests, government policies and business strategies. The subjects of these processes are the plural and massive interactive audiences which are defined as "Virtual communities". While Castells, evaluates these relationships between new media and social networks, he emphasizes of creation and reproduction of a culture which includes all these relations and transformations. Whereas the virtual communities, which are the subjects of the interactive communication in a multimedia environment, also constitutes today's Culture of Real Virtuality.

In the sixth chapter, Castells starts to examine the "Network Society" through space and time notions. He discusses the relationship between technology, economy and society by emphasizing the transformed perception of time and space in the information society with the concept of "Space of Flows". In the sixth chapter, one of the basic discussions is about the informational cities as practical spatial organizations. Castells, unlike many classic social science theories which assume that the extension was dominated by time, assumes that in the network society space organizes time. The developing service sector and the global flow of information are the components which constitute the "new industrial space". According to this, time is getting more flexible and space is getting more singular since people are moving back and forth between the spaces in a more mobile way. At this point, Castells examines the transformation of the urban form, which indicates the spatial dimension of the informational, economic, and socio-cultural transformations and offers a typology of this space, by considering United States, Europe and Mega-cities. In this context, he applies to the notion of the space of flows. The space of flows is the tangible organization of social practices which occurs processing trough a flow. With the arrival of the flow of spaces, the meaningful relationship between architecture and society was blurred. The flow of spaces is not spaceless but its structural logic is spaceless.

In the seventh chapter, the Notion "Timeless Time", which indicates an infinite value creation process of labor, draws attention. According to Castells, the flow of spaces, dissolves the time by disrupting the order of events, making them simultaneously and prevailing permanent impermanence in the society. With the new communication technologies time is compressed. Also, the culture of real virtuality contributes the transformation of the time with the concepts of "concurrency" and "timelessness". Overcoming the time is located at the core of the new forms organization which is defined as "Network Institution". Capital's being independent of time and culture's escaping from clock has dramatically eased and it has become distinctive for the structure of the network society with the emergence of the new information technologies. Castells explains this evaluation with the conceptualization "Global Casino" which he defines as a unified global capital market because capital is able to move between economies within seconds through the stock market. 
In the conclusion part of the book, Castells makes an integrated assessment through the dynamics which he defines within the framework of their interaction with the network society. Castells draws attention to beginning of Information age, which is increasingly organized around networks. He also emphasizes that in Network Society conditions in unreal economy has occurred, and while the capital is being controlled globally, the labor is getting individualized. However, in his evaluations, especially in his descriptions about the information age, Castells doesn't draw a fully optimistic picture. The final statements of the book summarize his pessimistic attitude: “...It is the beginning of a new existence, and indeed beginning of a new age, the Information Age, marked by the autonomy of culture vis-à-vis the material bases of our existence. But this is not necessarily an exhilarating moment. Because, alone at last in our human world, we shall have to look at ourselves in the mirror of historical reality. And we may not like the vision" (Castells, 2010, p.509).

As a result, the author presents an easily understandable and comprehensive analysis by examining the economic, social, cultural changes that caused by the Network Society, with the examples from different parts of the world, and by analyzing various economic, cultural and social structures in the context of "Network Institution". He does this by being as realistic as possible and reaching a clear conclusion by supporting his claims with various statistics.

Correspondence: Taner Kizilhan, Researh Assistant, Department of Communication Design and Management, Faculty of Communication Sciences, Anadolu University, Yunus Emre Campus, Eskisehir, Turkey 